\title{
Spiral CT virtual bronchoscopy with multiplanar reformatting in the evaluation of post-intubation tracheal stenosis: comparison between endoscopic, radiological and surgical findings
}

Mohamed Shehata Taha $\cdot$ Badr Eldin Mostafa •

Marwa Fahmy • Maha Khaled A. Ghaffar •

Enas Abdel Ghany

Published online: 27 January 2009

(c) Springer-Verlag 2009

Erratum: Eur Arch Otorhinolaryngol

DOI 10.1007/s00405-008-0854-y

Owing to an unfortunate oversight, the wrong figures were published in this article. The correct figures are shown here together with their legends.

Fig. 1 a Sagittal reconstruction showing a suprastomal stenosis. b Virtual endoscopic view showing the lesion
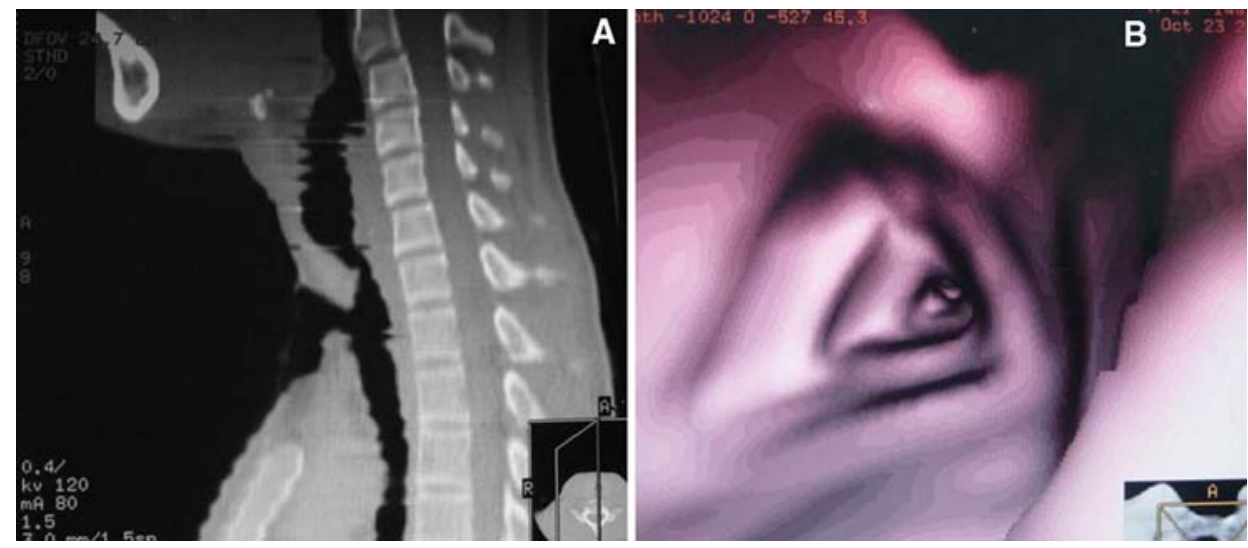

The online version of the original article can be found under doi:10.1007/s00405-008-0854-y.

M. S. Taha · B. E. Mostafa ( $\square)$

The Department of Otorhinolaryngology,

Ain-Shams University, 48 Ibn el Nafeess Street,

Nasr City, Cairo 11371, Egypt

e-mail: bemostafa@entainshams.com; bemostafa@yahoo.com

M. Fahmy · M. K. A. Ghaffar · E. A. Ghany

The Department of Radiology, Ain-Shams University,

48 Ibn el Nafeess Street, Nasr City, Cairo 11371, Egypt 


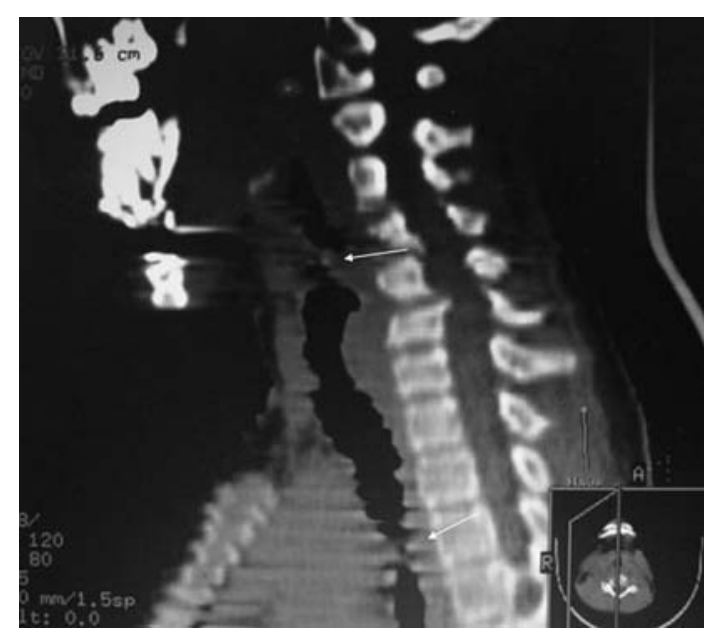

Fig. 2 Sagittal reconstruction showing two levels of stenosis 